\title{
THE THERMAL CHARACTERISTICS OF GYPSUM BOARDS WITH PHASE CHANGE MATERIALS (PCM)
}

\author{
D.Bajare, J.Kazjonovs, A.Korjakins \\ Riga Technical University, Institute of Materials and Structures \\ Department of Building Materials and Units \\ 1 Kalku str., LV 1658, Riga, Latvia \\ Ph.: + (371) 29687085, fax: + (371) 67089248, e-mail: diana.bajare@ rtu.lv
}

\begin{abstract}
Two types of PCM were investigated for use in phase change gypsum boards: salt hydrate and paraffin. The transition temperatures, or melting temperatures, of the PCM is near to standard or suggested room temperatures $20-21{ }^{\circ} \mathrm{C}$ for heating-dominated climates or $25-27{ }^{\circ} \mathrm{C}$ for cooling-dominated climates. Phase change gypsum boards were produced by using three different methods: simple immersion for 1 hour and direct incorporation of raw and microencapsulated PCMs in 5 and 10\% of composition mass. PCM were tested and the effects of energy conservation of PCM gypsum boards were determined. Also some physical and mechanical properties were determined to investigate the effect of PCM addition to gypsum boards.
\end{abstract}

Keywords: phase change materials, PCM, gypsum board.

\section{Introduction}

Overheat of indoor is a large problem not only in the southern countries, but it is becoming actual also in the Nordic countries as we saw in the last summer. In buildings with massive masonry or concrete walls, comfortable summer temperatures dominate due to the high heat capacity of components and assemblies. In contrast, buildings with modern lightweight constructions have little comparable heat storage, resulting in summers overheating as a major problem. The highly glazed surfaces in modern office buildings have an additionally significant influence here. Air condition, of course, is a solution, but it is electricity consumption and leads of peak periods of energy used. A possible answer to this problem is the emplacement of PCM, thereby increasing the thermal mass of buildings.

Materials with good thermal storage capacity are typically solid and heavy. They store proportionally more heat as they become hotter. PCM materials use the energy stored in a phase transition, normally liquid/solid, to store thermal energy in a narrow temperature range. PCM uses special paraffin, hydrated salts or eutectic mixtures to absorb heat to stabilize room temperature in the human comfort range between $21^{\circ} \mathrm{C}-26^{\circ} \mathrm{C}$. During the day PCM absorbs surplus heat by melting the paraffin, hydrated salts or eutectic mixtures encapsulated in microcapsules. During the cooler night the heat is released and the paraffin re-crystallizes, ready for another cycle the following day.

Energy storage in the walls, ceilings and floors of buildings may be enhanced by encapsulation suitable PCM within these surfaces to capture solar energy directly and increase human comfort by decreasing the frequency of internal air temperature swings and maintaining temperature closer to the desired temperature for a longer period of time. Therefore the thermal mass of the building materials is increased by the latent heat, but indoor air temperature can be reduced [1-4].

The idea of improving the thermal buffer thought the application of phase change materials has been common knowledge for many years, but until now they are not widely distributed in building industry of developed countries and almost non-known in Latvia.

Shiley et al. [5] investigated impregnation of the wallboards with PCM which was achieved by immersing gypsum wallboards in a bath filled with a constant volume of PCM for 6-10 min. In experiments, the PCM absorbed by the gypsum was about $26 \%$ of total weight 
(saturation is about 30\%). He proved that DSC tests could be used successfully to predict thermal performances of PCM wallboards.

Previous work has shown that wallboard can be successfully manufactured to contain up to 30 percent PCM, thus enabling this common building material to serve as a thermal energy storage device. The PCM wallboard was analyzed for passive solar applications and found to save energy with a reasonable payback time period of five years [6].

Athienitis et al. [7] presented the full-scale experiment results that demonstrated the application of PCM-gypsum boards in a passive solar building can bring down the maximum room temperature by about $4{ }^{\circ} \mathrm{C}$ during the day, thus preventing overheating, and during the evening and night (7-11 h in total) the surface temperature of the PCM gypsum board was approximately $3.2{ }^{\circ} \mathrm{C}$ higher than the surface temperature of the conventional wallboard so that heat was returned to the room.

Use of encapsulated PCM in building materials does not adversely affect the function of the construction material. Experiments with macroencapsulation failed due to poor conductivity of the phase change material where effective heat transfer was prevented. With microencapsulation, the dimensions are so small that this effect does not occur [8].

Hence, the aim of this work is to create a composition of comercially available gypsum and PCMs by using immersion, incorporation and encapsulation methods. Finally the mechanical, physical and thermal properties of created gypsum samples with PCM were determined.

\section{PCMs used}

\section{Materials and methods}

The latent heat stored during melting and freezing offers particular benefits. The key asset of PCMs is their high thermal storage capacity, which, for unit thickness, is many times that of conventional building materials like gypsum, concrete, etc. Common PCMs include paraffins, salt hydrates, alcohols, fatty acids, and synthetic materials.

Paraffins are waxes. They are readily availabe, inexpensive and melt at different temperatures relating to their carbon chain length with the general formula $\mathrm{C}_{\mathrm{n}} \mathrm{H}_{2 \mathrm{n}+2}$. They are chemically stable, their volume increase upon melting is in the order of $10 \%$ of their volume; this is similar to that of many inorganic materials, but less critical as paraffins are softer and therefore build up smaller forces upon expansion. Paraffins are safe and non-reactive; they do not react with most common chemical reagents. Commercially available paraffins fromRubitherm RT21 and RT27 were used in this investigation [10]. The structure of paraffins taken with optical microscope with 40x magnification is shown in Fig. 1.

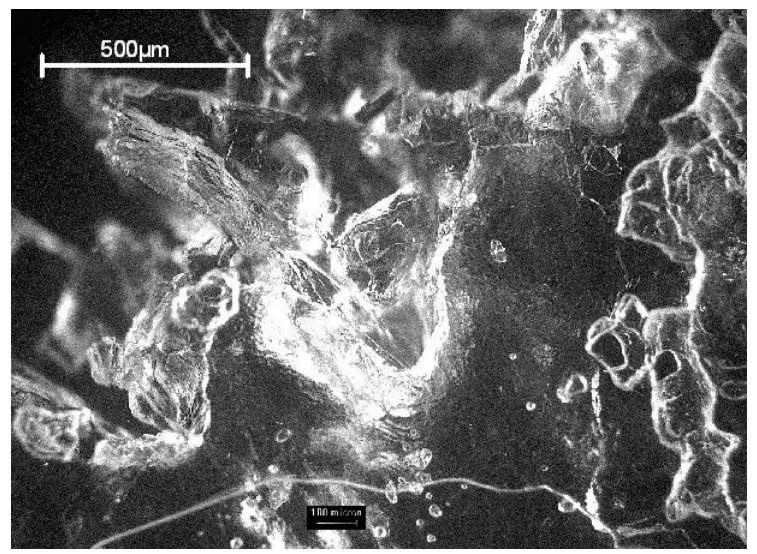

Fig.1. Structure of paraffins

Salt hydrates consist of salt and water, which combine in a crystalline matrix when the material solidifies. They are attractive materials for use in thermal energy storage due to high 
volumetric storage density, sharp melting point, show a lower volume change than paraffins and moderate costs compared to paraffin waxes. Among the disadvantages of salt hydrates is that they can potentially seperate into different phases and thus show problems with cycling stability and show super-cooling because they do not start to crystallize at the freezing point. Commercially available salt hydrates from Rubitherm SP22 and SP25 were used in this investigation [10]. The structure of salt hydrates taken with optical microscope with 40x magnification is shown in Fig. 2.

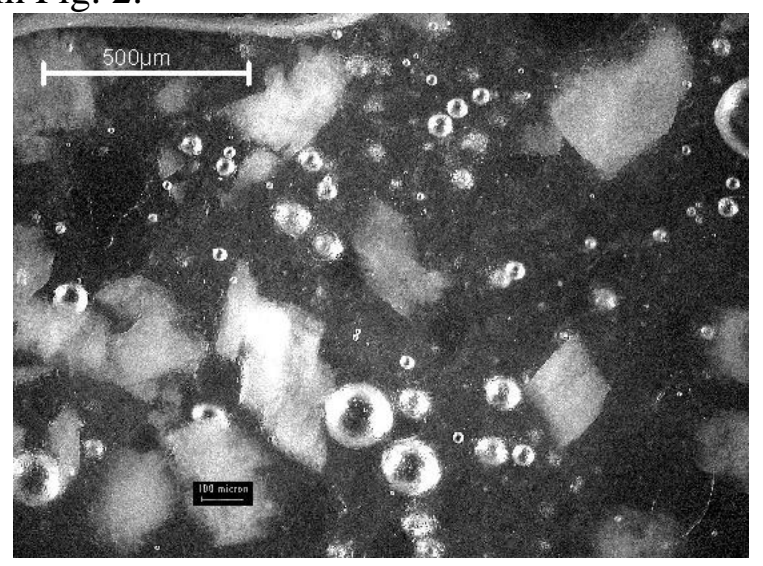

Fig.2. Structure of salt hydrates

Another product is encapsulated PCM, which prevents leakage of the material and improves the heat transfer. Encapsulations are classified according to their size as macroencapsulation and microencapsulation. In this paper are used two powder form microencapsulated paraffins DS5001 X and DS5008 X, with a typical crosslinked polymethyl methacrylate capsule diameter in the 2-20 $\mu \mathrm{m}$ range, produced by the company BASF [11]. The structure of microcapsules taken with optical microscope with 40x magnification is shown in Fig. 3.

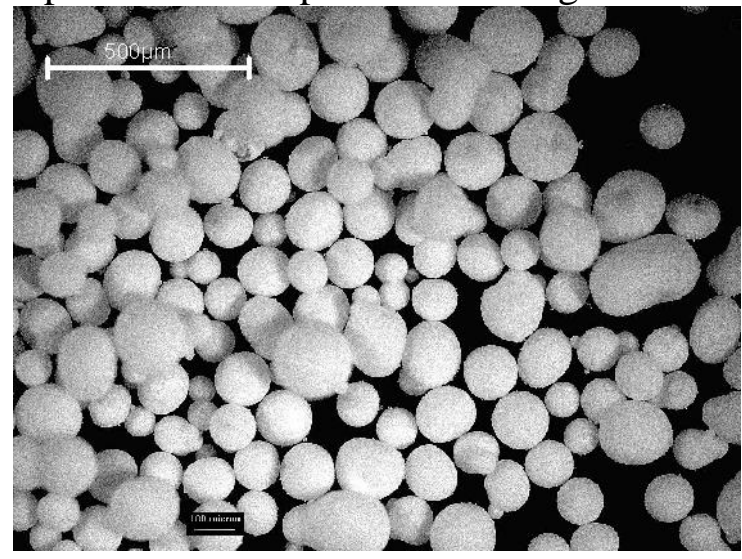

Fig.3. Structure of microcapsules

Thermo-physical properties of PCMs used in this paper are shown in Table 1.

Table 1.

Thermo-physical properties of PCMs [10, 11]

\begin{tabular}{|c|c|c|c|c|c|c|c|}
\hline Property & & RT21 & RT27 & SP22 & SP25 & DS5001X & DS5008 X \\
\hline Melting point $\left({ }^{\circ} \mathrm{C}\right)$ & & 21 & 28 & 22 & 25 & 26 & 23 \\
\hline \multirow[t]{2}{*}{ Density $\left(\mathrm{kg} \mathrm{m}^{-3}\right)$} & liquid & 760 & 770 & 1430 & & & \\
\hline & solid & 880 & 880 & 1490 & 1380 & & \\
\hline Bulk density (kg m-3) & & & & & & 350 & 350 \\
\hline
\end{tabular}




\section{DSC analysis}

Differental scanning calorimeter (DSC) analysis with heating rate of $1{ }^{\circ} \mathrm{C} / \mathrm{min}$ was used to evaluate the thermal characteristics of PCMs. The results are summarized in Table 2.

Table 2

\section{DSC analysis of PCMs}

\begin{tabular}{llcc}
\hline Material & Heat of fusion $\left(\mathrm{J} \mathrm{g}^{-1}\right)$ & Melting peak point $\left({ }^{\circ} \mathrm{C}\right)$ & Temperature range $\left({ }^{\circ} \mathrm{C}\right)$ \\
\hline RT21 & 148.0 & 22.9 & 6.5 to 27.0 \\
RT27 & 150.3 & 26.7 & 14.3 to 28.4 \\
SP22 & 109.1 & 20.7 & 0.9 to 26.9 \\
SP25 & 110.9 & 29.8 & 21.1 to 33.1 \\
DS5001 X & 99.8 & 26.9 & 18.7 to 29.1 \\
DS5008 X & 95.6 & 23.1 & 13.2 to 25.2 \\
\hline
\end{tabular}

It is seen that the highest heat of fusion is for paraffins RT21 and RT27. For better performance of PCM usage for latent heat storage, it is relevant that the melting range is narrow and as close as possible to the melting point. The melting transitions which are shown in Fig. 4 for RT 27, SP25 and DS $5001 \mathrm{X}$ are much sharper than for the rest ones, which means that they are more suitable for building applications.

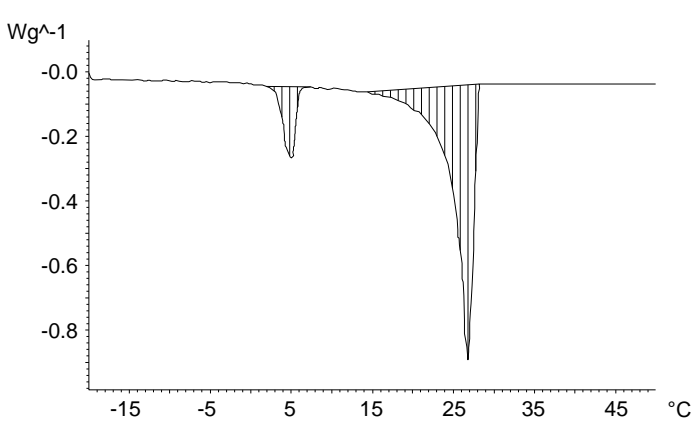

a)

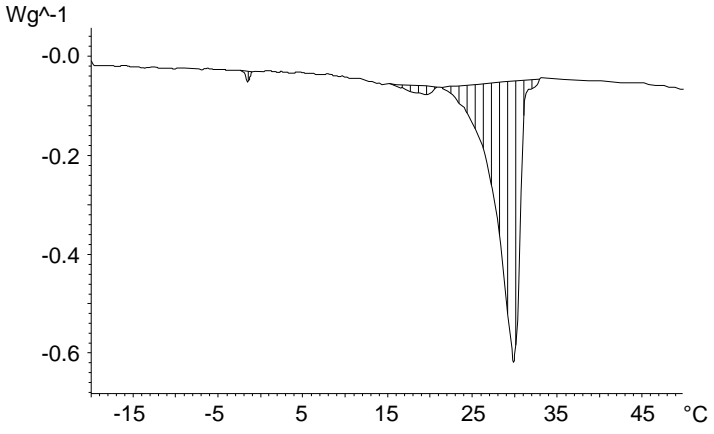

b)

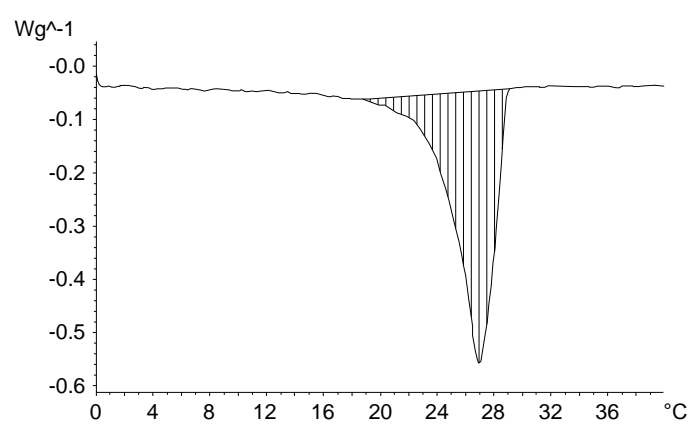

c)

Fig.4. DSC-measurements of PCMs (a-RT27, b-SP25, c-DS5001 X)

\section{Experimental methods}

Direct incorporation may be the most economical method, because very little additional process equipment is required. Paraffins and salt hydrates were added to local commercially available gypsum in 5 and $10 \%$ of compositions mass in the mixing process. Components were batched and then mixed in the laboratory drum mixer for 2 minutes. 
In immersion method, the porous gypsum material was dipped into the hot melted paraffins and salt hydrates, which were absorbed into the pores by capillary action. After 1 hour the gypsum was removed from the liquid PCM and allowed to cool and the PCM remained in the pores of the gypsum.

Microencapsulated PCM in powder form was incorporated into the gypsum composition in 5 and $10 \%$ of mass.

To establish the influence of the PCM material on mechanical and physical properties of gypsum, standard testing methods were used. The mechanical and physical properties (flexural and compressive strength and material density) were determined after 7 days according to LVS 150:1998/A1:2002. For the evaluation of thermal characteristics DSC analyses were performed for the several gypsum compositions.

\section{Results and discussion}

By immersing gypsum in PCM it was feasible to absorb $150 \mathrm{~kg} / \mathrm{m}^{3} \mathrm{SP} 22$ or $11.4 \%$ of composition mass, $84.8 \mathrm{~kg} / \mathrm{m}^{3} \mathrm{SP} 25$ or $6.8 \%, 303 \mathrm{~kg} / \mathrm{m}^{3} \mathrm{RT} 21$ or $20.6 \%$ and $300 \mathrm{~kg} / \mathrm{m}^{3} \mathrm{RT} 27$ or $20.4 \%$. It is obvious that a higher mass ratio can be achieved by using paraffins than salt hydrates. The flexural, compressive strength and material density of gypsum immersed in PCM for 1 hour are shown in Table 3.

Table 3.

\begin{tabular}{clllll}
\multicolumn{1}{l}{ Mechanical and physical properties of gypsum samples immersed in PCMs } \\
\hline Property & Standard & SP22 & SSP25 & RT21 & RT27 \\
\hline Density kg m-3 & 1120 & 1315 & 1245 & 1470 & 1470 \\
\hline Flexural strength MPa & 4.1 & 1.8 & 2.1 & 3.7 & 3.9 \\
Reduction \% & & $55.5 \%$ & $49.2 \%$ & $9.4 \%$ & $4.7 \%$ \\
\hline Compressive strength MPa & 7.4 & 3.7 & 4.3 & 7.2 & 7.1 \\
Reduction \% & & $49.9 \%$ & $42.2 \%$ & $2.9 \%$ & $4.2 \%$ \\
\hline
\end{tabular}

It is seen that the flexural and compressive strength for salt hydrate gypsum samples are reduced for maximum of 55.5\% compared to the standard gypsum sample. At the same time for paraffins the reduction in strength is maximum of $9.4 \%$.

The flexural, compressive strength and material density results for gypsum samples made by direct incorporation method with raw and microencapsulated PCMs are shown in Table 4.

Table 4.

Mechanical and physical properties of gypsum samples incorporated with PCMs

\begin{tabular}{clccccc}
\hline $\begin{array}{c}\text { PCM mass of } \\
\text { composition }\end{array}$ & Name & $\begin{array}{l}\text { Density } \\
\mathrm{kg} \mathrm{m}^{-3}\end{array}$ & $\begin{array}{l}\text { Flexural } \\
\text { strength } \\
\mathrm{MPa}\end{array}$ & $\begin{array}{l}\text { Reduction } \\
\%\end{array}$ & $\begin{array}{l}\text { Compressive } \\
\text { strength } \\
\mathrm{MPa}\end{array}$ & $\begin{array}{l}\text { Reduction } \\
\%\end{array}$ \\
\hline 0 & Standard & 1115 & 4.1 & & 7.4 & \\
5 & SP25 & 1035 & 2.1 & $48.9 \%$ & 3.4 & $53.7 \%$ \\
10 & SP25 & 1015 & 1.8 & $55.5 \%$ & 2.5 & $66.6 \%$ \\
5 & SP22 & 1050 & 2.3 & $42.1 \%$ & 3.0 & $60.1 \%$ \\
10 & SP22 & 1020 & 0.9 & $78.9 \%$ & 1.2 & $83.3 \%$ \\
5 & DS5001 & 1025 & 3.7 & $9.7 \%$ & 6.8 & $8.3 \%$ \\
10 & DS5001 & 950 & 2.6 & $34.8 \%$ & 5.3 & $28.0 \%$ \\
5 & DS5008 & 1020 & 3.5 & $13.2 \%$ & 6.2 & $16.9 \%$ \\
10 & DS5008 & 970 & 3.2 & $20.0 \%$ & 5.6 & $24.1 \%$ \\
\hline
\end{tabular}


Using direct incorporation method was concluded that paraffin cannot be mixed into gypsum with ordinary methods. It was obvious that salt hydrates are not suitable for direct incorporation method because the strength reduction for mass composition of $5 \%$ was maximum of $60.1 \%$, but for $10 \%$ mass composition $-83.3 \%$. The microencapsulated PCMs with $5 \%$ mass composition showed maximum of $16.9 \%$ strength reduction, but $10 \%-34.8 \%$ strength reduction.

\section{DSC analysis of immersed gypsum samples}

DSC analysis which are shown in Fig. 5 of immersed gypsum samples SP 25 and RT21 were carried out with heating rate of $1{ }^{\circ} \mathrm{C} / \mathrm{min}$. The results show that paraffin after absorbtion still keeps the thermal properties and the gypsum sample has a heat of fusion of $26.4 \mathrm{~J} \mathrm{~g}^{-1}$ with the melting peak point of $24^{\circ} \mathrm{C}$. Theoretical calculations showed that sample with absorbed PCM the heat of fusion should be $30.5 \mathrm{~J} \mathrm{~g}^{-1}$, which could be explained by irregular PCM dissipation through the sample. Salt hydrates lost their thermal properties and showed only $1.4 \mathrm{~J} \mathrm{~g}^{-1}$ with melting point of $24.9^{\circ} \mathrm{C}$, but theoretically the heat of fusion should be $7.5 \mathrm{~J} \mathrm{~g}^{-1}$.

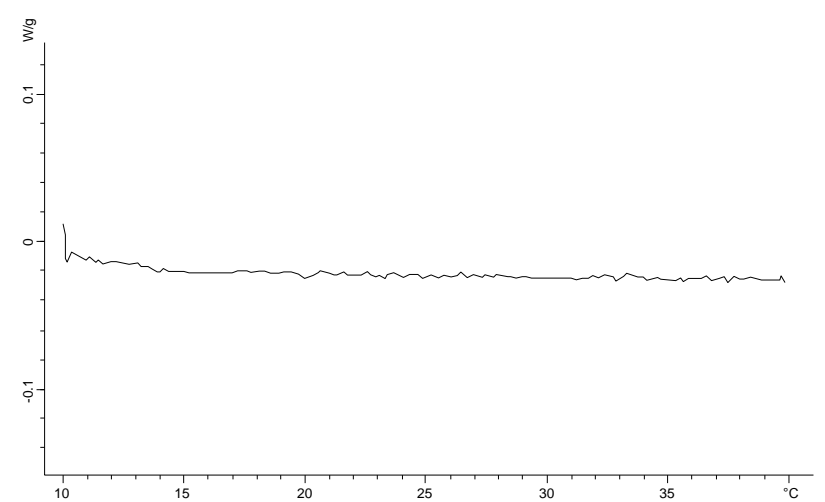

a)

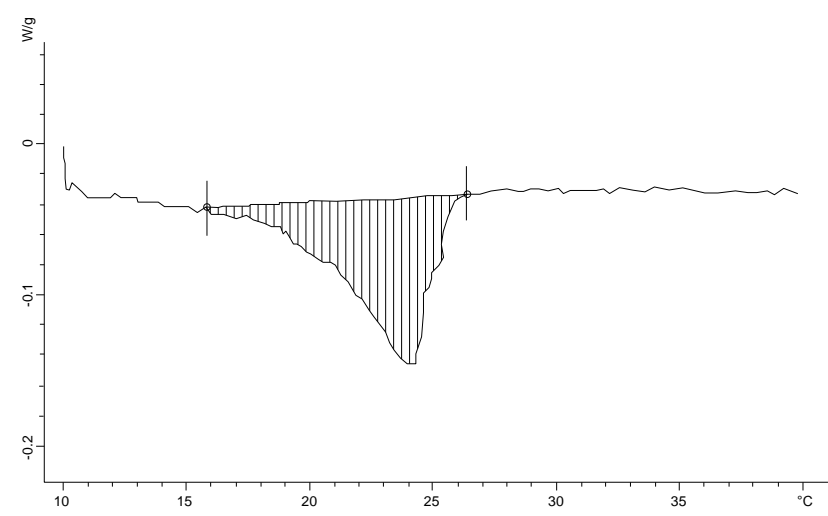

b)

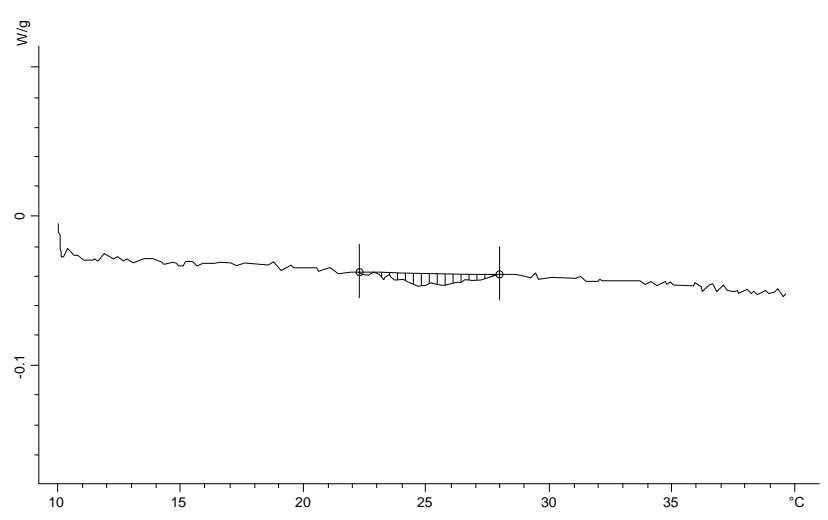

c)

Fig.5. DSC-measurements of gypsum samples

(a - gypsum, b-gypsum immersed in RT21, c-gypsum immersed in SP25)

\section{Conclusions}

The heat of fusion for raw PCMs is higher of microencapsulated PCM, because of the inert polymer shell.

Although, the raw materials are not suitable for the direct incorporation method, because for paraffins there was a problem with mixing, but for salt hydrates the strength decrease was unacceptable high and the thermal properties were not stable due to changes of hydratation level of the chemical composition of PCM. 
For the immersion method salt hydrates also decreased the strength unacceptably high, but paraffin showed good results with only $9.4 \%$ lost in strength and $26.4 \mathrm{~J} \mathrm{~g}^{-1}$ heat of fusion.

This investigation shows that potentially easy way of PCM incorporation in gypsum is microencapsulation with a polymer shell. Microencapsulation is the next aim for further research work.

\section{References}

1. Schossig, P., Henning, H.-M., Gschwander, S. Micro-encapsulated phase-change materials integrated into construction materials. Solar Energy Materials \& Solar Cells 89, 2005, p. 297-306.

2. Harland, A., Mackay, C., Vale, B. Phase change materials in architecture. Victoria University of Wellington, 2010, p. 11.

3. Kenisarin, M., Mahkamov, K. Solar energy storage using phase change materials. Renewable and Sustainable Energy Reviews 11, 2007, p. 1913-1965.

4. Tyagi, V.V, Buddhi, D. PCM thermal storage in buildings. Renewable and Sustainable Energy Reviews 11, 2007, 1146-1166.

5. Shilei, L., Guohui, F., Neng, Z., Dongyan, L. Experimental study and evaluation of latent heat storage in phase change materials wallboards. Energy and buildings 39, 2007, p. 1088-1091.

6. Stoval, T. K., Tomlinson, J. J. What are the potential benefits of including latent storage in common wallboard. Journal of Solar Energy Engineering, 2008, p. 318-325.

7. Athienitis, AK., Liu, C., Hawes, D., Banu, D., Feldman, D. Investigation of the thermal performance of a passive solar-test room with wall latent heat storage. Build Environ, 1997, p. 405-410.

8. Hawlader, M.N.A, Uddin, M.S, Khin M.M. Microencapsulated PCM thermal-energy storage syst. Applied energy 74, 2003, p. 195- 202.

9. LVS 150:1998 /A1:2002. Gypsum building plaster - Definitions, requirements, tests, marking. LVS. Riga, 2002. 20 p.

10. Rubitherm Gmbh. http://www.rubitherm.com/english/index.htm.

11. BASF The Chemical Company. http://worldaccount.basf.com/wa/EU en_GB/Catalog/ACIndustry/pi/ BASF/segment/ new_building_materials. 